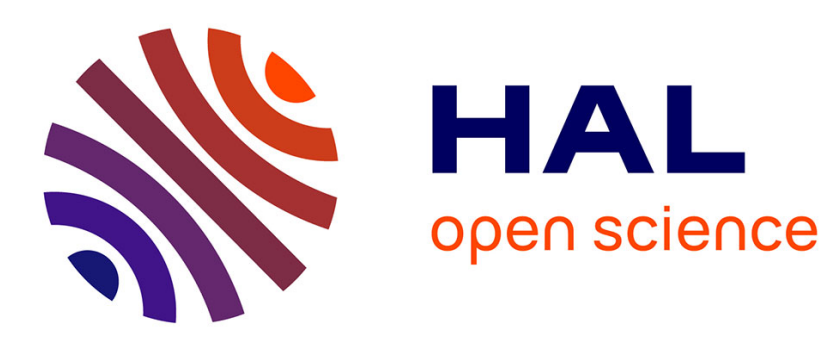

\title{
Taylor's Test Technique for Dynamic Characterization of Materials: Application to Brass
}

\author{
R. Julien, T. Jankowiak, A. Rusinek, P. Wood
}

\section{To cite this version:}

R. Julien, T. Jankowiak, A. Rusinek, P. Wood. Taylor's Test Technique for Dynamic Characterization of Materials: Application to Brass. Experimental Techniques, 2013, 10.1111/ext.12070 . hal01633534

\section{HAL Id: hal-01633534 \\ https://hal.science/hal-01633534}

Submitted on 11 Jan 2018

HAL is a multi-disciplinary open access archive for the deposit and dissemination of scientific research documents, whether they are published or not. The documents may come from teaching and research institutions in France or abroad, or from public or private research centers.
L'archive ouverte pluridisciplinaire HAL, est destinée au dépôt et à la diffusion de documents scientifiques de niveau recherche, publiés ou non, émanant des établissements d'enseignement et de recherche français ou étrangers, des laboratoires publics ou privés. 


\title{
Taylor's Test Technique for Dynamic Characterization of Materials: Application to Brass
}

\author{
R. Julien ${ }^{1}$, T. Jankowiak ${ }^{2}$, A. Rusinek ${ }^{1}$, and P. Wood ${ }^{3}$ \\ 1 Laboratory of Mechanics, Biomechanics, Polymers and Structures, National Engineering School of Metz, Metz, France \\ 2 Institute of Structural Engineering, Poznan University of Technology, Poznan, Poland \\ 3 DMEM, University of Strathclyde, Glasgow, UK
}

Keywords

Dynamic Fracture, Dynamic Behavior, Taylor Test, Experiments, Brass

\begin{abstract}
The article reports experiments using the Taylor test to define the dynamic behavior of brass. This material does not exhibit strain rate dependency therefore it allows the validation of an analytical description of flow stress as a function of strain with strain hardening for the data obtained from the Taylor test. The experiment is used to study the process of damage and fracture with fragmentation which is dependent on the impact velocity. Using the experimental data a numerical model of the Taylor test is developed to determine the strain level and the strain gradient along the specimen.
\end{abstract}

\section{Introduction}

To define the material behavior for application in design, it is necessary to perform several different tests to understand the effect of different loading paths, strain rates, and temperatures on the material behavior. As shown in Fig. 1, several techniques have to be used to sweep a wide range of strain rates. Coupling all the data from different tests enables the definition of the strain rate sensitivity of the material across a wide range of strain rates. To reach high strain rates the Split Hopkinson pressure bar (SHPB) or Taylor's test is necessary (Fig. 1). At lower strain rates the Taylor test or a high rate servo-hydraulic machine may be used.

In this article, the Taylor test is used to define the dynamic behavior of material. The nonlinear strain rate sensitivity of materials at high strain rate is an important measurement in the constitutive model as reported in Ref. 1. For metals, the nonlinear strain rate sensitivity is reached at a transition strain rate $\dot{\epsilon}_{\text {transition }} \approx 100 \mathrm{l} / \mathrm{s}$.

It is also frequently observed that the failure mode and fracture are dependent on the dynamic behavior of the material and in particular the initial impact velocity. The Taylor test is a useful way to define the velocity or strain rate transition between failure modes. The failure modes observed in a material at high strain rate are typically crack propagation, ${ }^{2-4}$ shear failure, or crack formation resulting from adiabatic shear bands. ${ }^{5}$ The failure mode is in a general way dependent on the hardness of the material. ${ }^{4}$ The main goal of this work is to establish a method and model to analyze the results obtained from the Taylor test.

\section{Material Definition}

Quasi-static and dynamic behavior of brass The material used in this work is brass with zinc varying from 42 to $44 \%$ of the weight, and the rest of the alloy is copper. In term of hardness, the copper is softer when compared with zinc, inducing a brittle behavior at high impact velocity. To describe the material behavior, several compression tests are performed to develop the range of strain rates in the material using quasi-static and dynamic tests (Fig. 2). The quasi-static tests are performed using 


\begin{tabular}{|c|c|c|c|c|c|}
\hline Strain rate $(1 / 5)$ & $10^{-4}$ & $10^{-4}$ & $510^{2}$ & $810^{2}$ & $10^{4}$ \\
\hline \multirow{3}{*}{ Set-up } & $\begin{array}{c}\text { Creep } \\
\text { and Relaxation }\end{array}$ & Quasi-static & Intermediate & Dynamic & $\begin{array}{l}\text { Impact } \\
\text { plate-plate }\end{array}$ \\
\hline & \multicolumn{2}{|c|}{ Conventional cross head device } & Hydraulic & Hopkinson bar & Plate impact \\
\hline & & Hydraulic & & Tayior test & Taylor test \\
\hline
\end{tabular}

Figure 1 Definition of the devices used to deliver the range of strain rates in mechanical testing.

a compression screw actuated machine. The dynamic high rate tests are performed using SHPB, which is capable of reaching a strain rate of $\dot{\epsilon}_{\max } \approx 5000 \mathrm{l} / \mathrm{s}$. The dynamic behavior of the material is described by measuring of the elastic waves that develop in the test bars and is reported in Ref. 6. The diameter of the specimens for dynamic testing is $\phi_{\text {specimen }}=6 \mathrm{~mm}$ and length $h_{\text {specimen }}=3 \mathrm{~mm}$. The specimens are cut from an extruded bar. This geometry has been shown to reduce friction and inertia. ${ }^{6,7}$ The friction effect is further mitigated by using a MoS2 grease between the specimen contact surfaces and bars. The results obtained for quasi-static and dynamic compression tests are displayed (Fig. 2). Some tests have been done in quasi-static compression for different initial temperatures in the range $300 \mathrm{~K} \leq T \leq 573 \mathrm{~K}$. The strain rate for quasi-static testing is $\dot{\epsilon}=0.001 \mathrm{l} / \mathrm{s}$. The temperature sensitivity is determined as $v=$ $\partial \sigma /\left.\partial T\right|_{\epsilon, \dot{\epsilon}}=-0.319 \mathrm{MPa} / \mathrm{K}$.

It is observed in the Fig. 2(a) that brass exhibits no strain rate sensitivity, with the exception to the slope at the start of loading. This is due to the elastic wave rising time. This rising time and slope are influenced by the dimensions of the SHPB test device and in particular the diameter of the test bar. ${ }^{8}$ The quasistatic tests performed at different initial temperatures are used to define the temperature sensitivity of the material in the Johnson-Cook (JC) model (Fig. 2(b)) allowing to reach a stress level equal to zero for melting temperature.

Verification of Taylor's test-dynamic behavior and failure

A Taylor test will enable the definition of a single coordinate in the stress-strain curve at a given strain rate. Thus, it is necessary to perform several tests to fully define the material behavior under dynamic loading. To define the parameters of a constitutive relation a process of optimization is necessary. The results are determined from the initial and final geometry of the specimen after impact on a rigid surface. At high impact velocity the Taylor test is used to establish the mode of dynamic failure in the specimen material.

In this article, Taylor tests are performed using a pneumatic gas gun with a maximum pressure of $P_{0}=16$ bars (Fig. 3). The specimen is launched along the tube $\mathrm{C}$ and impacts a rigid wall perpendicular to its long axis E. To provide a hard and strong rigid surface for the impacted surface, tungsten alloy is used which has a yield stress typically $\sigma_{y} \approx 2 \mathrm{GPa}$. The stiffness of the impacted structure is very high with additional ribs. On the reverse side of the Tungsten layer a high strength steel bolster has been added to provide a stiff inflexible arrangement for the impacted structure (Fig. 4(b)).

To perform the Taylor's test cylindrical specimens have been machined with the following dimensions: diameter $\phi_{\text {specimen }}=8 \mathrm{~mm}$ and length $h_{\text {specimen }}=40 \mathrm{~mm}$ (see Fig. 4). The mass of each specimen $m_{\text {specimen }}=17 \mathrm{~g}$. The maximum speed of the test is $V=200 \mathrm{~m} / \mathrm{s}$. The internal diameter of the gas gun tube is $\phi_{\text {tube }}=13 \mathrm{~mm}$, hence a Sabot is used (Fig. 4(c)) to maintain the trajectory of the specimen on exiting the gas gun. The Sabot design is described in Ref. 9. The Sabot consists of two parts (Fig. 4(c)). At the impact end a ring with several notches is used in one part of the Sabot which exhibits a brittle behavior during the test, so that the process of plastic deformation of the test specimen is not disturbed by the sabot. A second part of the Sabot is designed to guide the specimen in the gas gun tube. The total mass of the sabot designed in a brittle polymer is $m_{\text {sabot }}=2.5 \mathrm{~g}$. The setup has been developed to ensure the angle in each direction to obtain a perpendicular impact (Fig. 4(b)).

The test setup is displayed in Fig. 3. The initial impact velocity is measured using two laser sensors in order to accurately determine the stress and strain rate in the specimen. The distance between the lasers sensors is $\Delta X_{12}$, and the rising time is $\Delta t_{12}$. The 

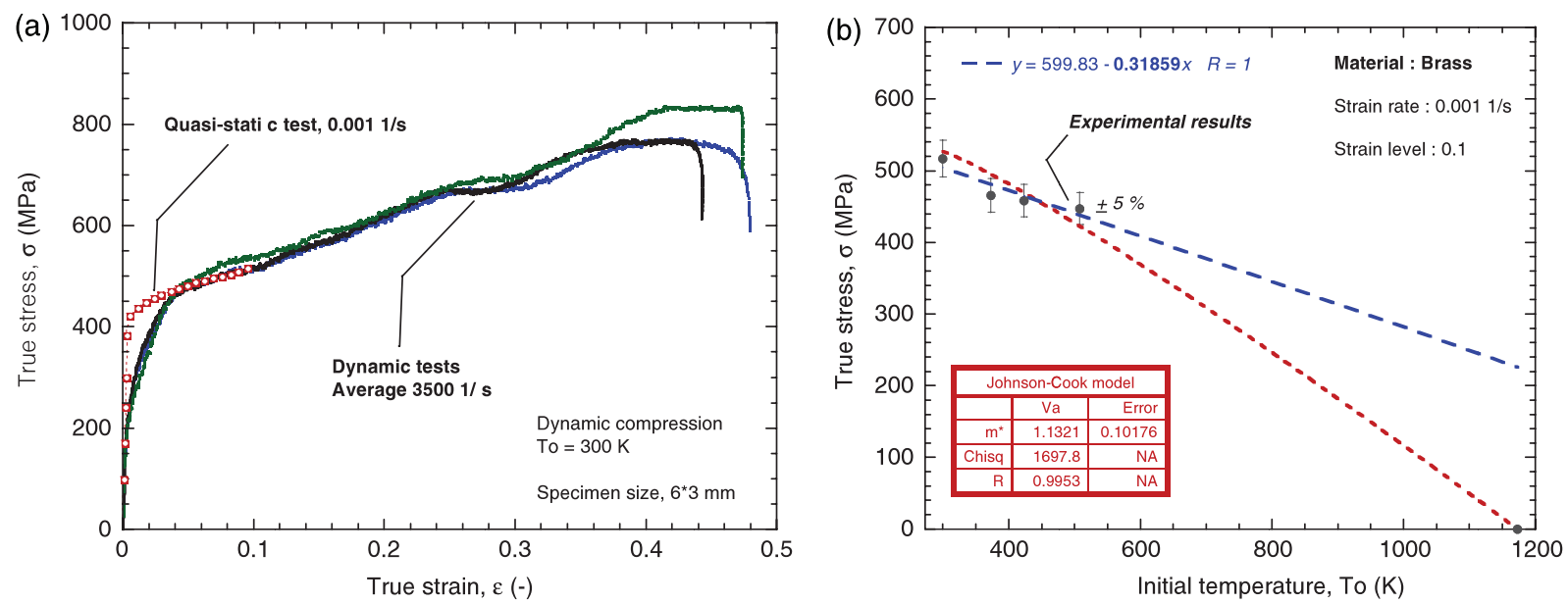

Figure 2 (a) True stress-strain test results obtained for Brass under quasi-static and dynamic loading; (b) determination of the thermal softening parameter $m^{*}$ using quasi-static results and melting temperature $(1177 \mathrm{~K})$.

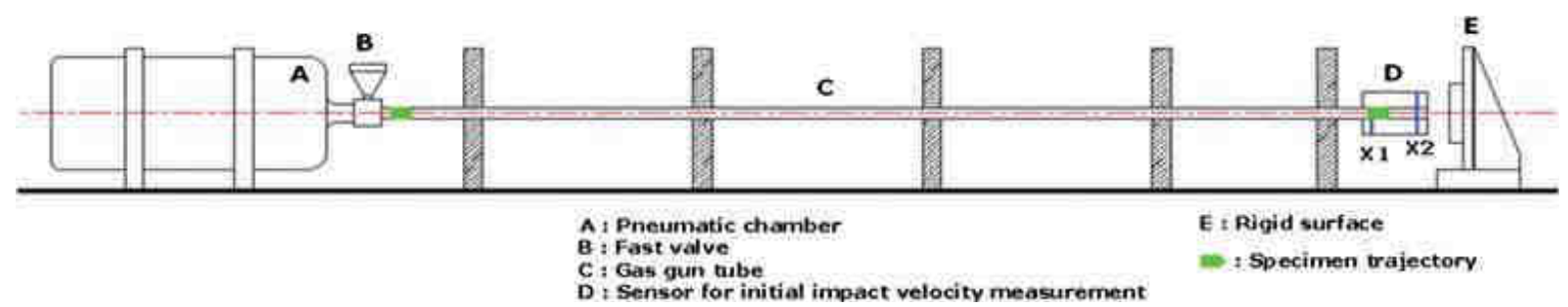

Figure 3 Air gas gun used to launch the specimen and setup for impact velocity measurement.
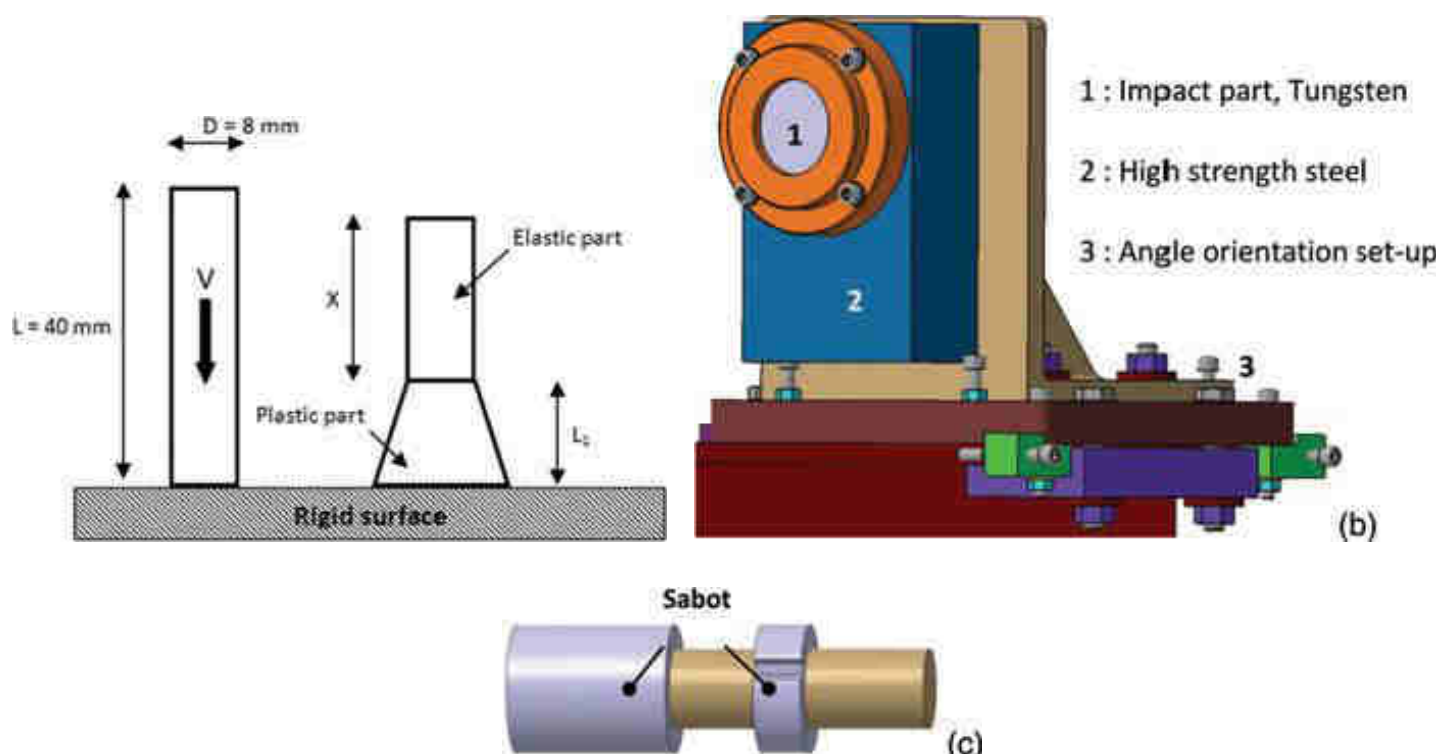

(c)

Figure 4 (a) Definition of the specimen geometry before and after impact to characterize the dynamic behavior of a material; (b) device used for the Taylor's test; (c) Sabot used for Taylor's test to ensure perpendicular impact. 


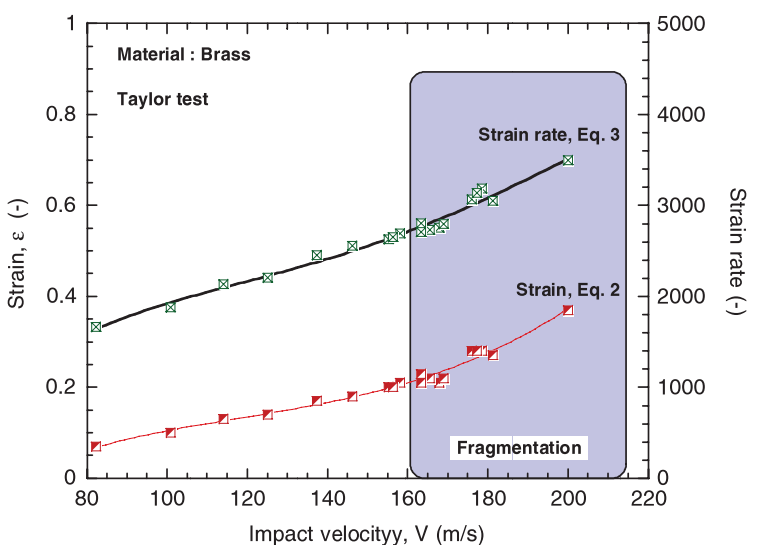

Figure 5 Effect of impact velocity on strain and strain rate levels attained.

velocity is calculated as follows:

$$
V=\frac{\Delta X_{12}}{\Delta t_{12}}
$$

The maximum error is estimated as $|\Delta V|=1 \mathrm{~m} / \mathrm{s}$. This was checked using two sensors coupled to a high speed camera and a constant velocity was observed, $\dot{V} \rightarrow 0$. The shape of the deformed specimen (Fig. 4(a)) is measured after the test. From which the strain $\epsilon$ and the strain rate $\dot{\epsilon}$ are derived in the specimen as follows ${ }^{10}$ :

$$
\begin{gathered}
\epsilon=-\ln \left(\frac{L_{1}-X}{L-X}\right) \\
\dot{\epsilon}=-\frac{V}{2\left(L-L_{1}\right)} \ln \left(\frac{L_{1}-X}{L-X}\right)
\end{gathered}
$$

The initial length of the specimen is $L$, the final length of the specimen is $L_{1}$, and the elastic (undeformed) part of the specimen is $X$ (Fig. 4(a)).

The range of measured impact velocities for the brass material tested at room temperature varies from 82 to $200 \mathrm{~m} / \mathrm{s}$ and the results are displayed in Fig. 5 .

The strain and strain rate increase with impact velocity $V$ (Fig. 5). A sigmoidal relationship is observed between the strain and the initial impact velocity $V$ in the range $80 \leq V \leq 170 \mathrm{~m} / \mathrm{s}$ (Fig. 5). The same relationship is observed between strain rate and initial impact velocity. The maximum strain in the specimen is 0.37 and the maximum strain rate is $3500 \mathrm{l} / \mathrm{s}$ for the impact velocity $V=200 \mathrm{~m} / \mathrm{s}$.

The failure modes in the specimen after impact are displayed in Fig. 6(b), and are influenced by the initial impact velocity. At lower impact velocity, radial cracks have formed on the external diameter of the specimen in the zone of plastic deformation. At higher impact velocity, the failure mechanism is characterized by the development of intense shear bands along the external surface of the specimen and a radial crack. At still higher impact velocities above $156 \mathrm{~m} / \mathrm{s}$, fragmentation is observed together with a cup cone failure mode. The number of fragments varies in the range $3 \leq N \leq 5$ which is dependent on the initial impact velocity (Fig. 6(a)). The fragmentation is due to the junction of different shear plans acting which develop under intense plastic deformation. A similar observation was reported for titanium alloy ${ }^{11}$ and magnesium alloy. ${ }^{12}$ As fragmentation develops, the linear relationship between strain and initial impact velocity no longer holds (Fig. 5).

In numerical simulations, a failure criterion will be necessary to model the failure processes in

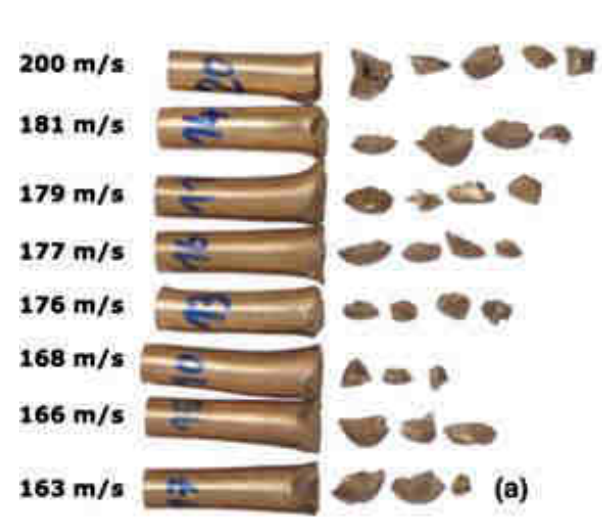

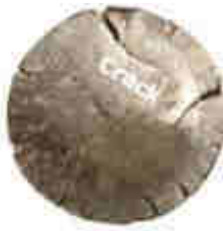

$156 \mathrm{~m} / \mathrm{s}$

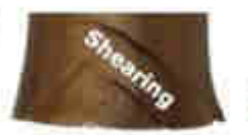

$163 \mathrm{~m} / \mathrm{s}$

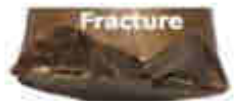

$176 \mathrm{~m} / \mathrm{s}$

(b)

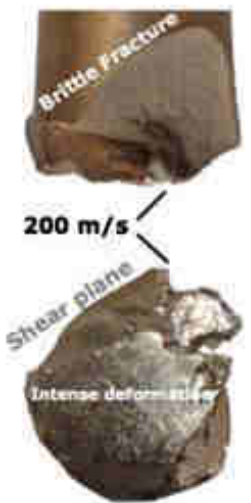

Figure 6 (a) Effect of different initial impact velocities on the deformed shape of deformed specimens and their fragmentation; (b) effect of initial impact velocity on the failure pattern. 

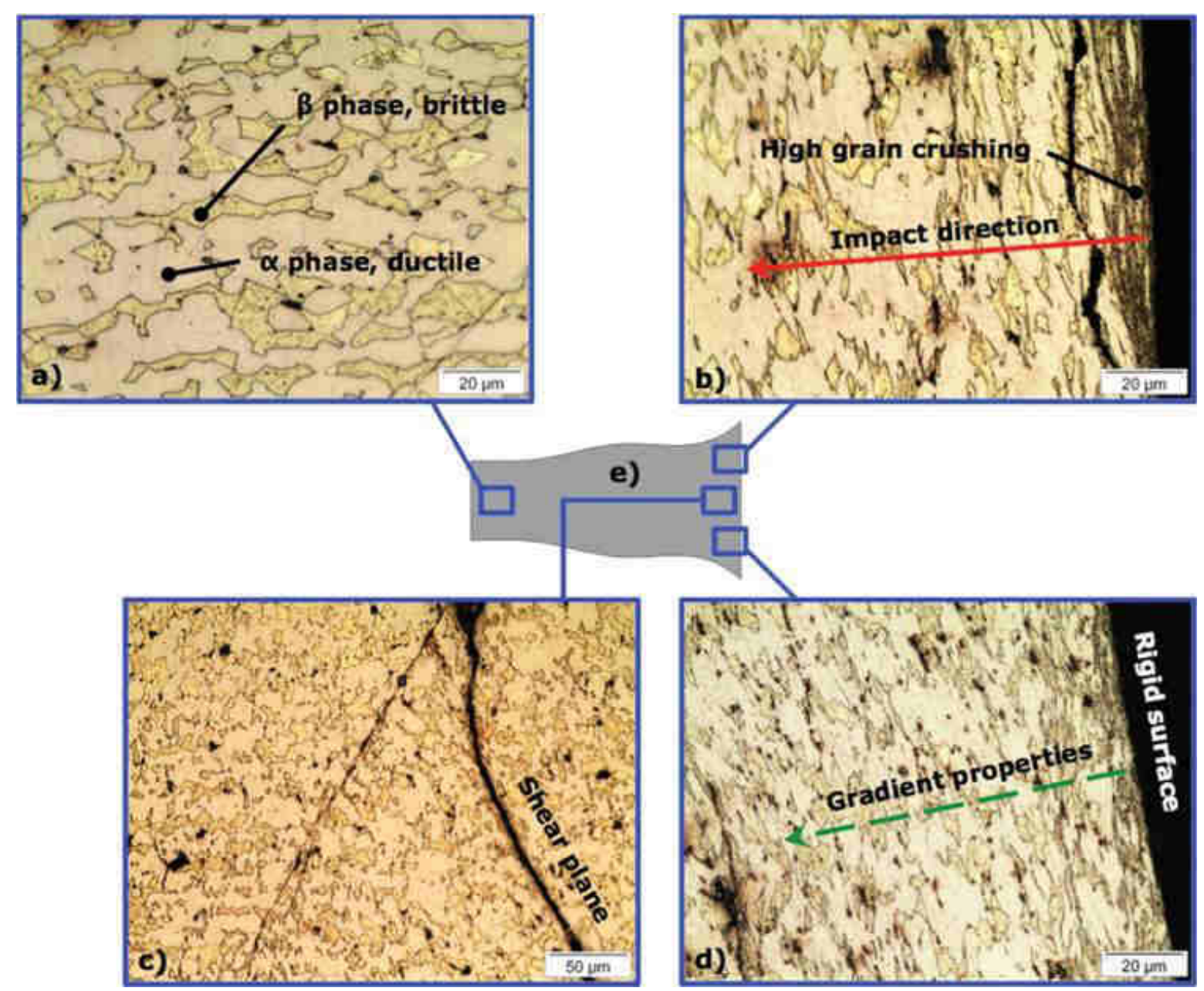

Figure 7 Change in grain structure after dynamic impact, $V=177.3 \mathrm{~m} / \mathrm{s}$; (a) in elastic part; $(b, c, d)$ close to the impact side.

the material at higher impact velocity. The stress triaxiality is the basis for one approach to model the initiation of failure and is discussed in Ref. 13. Examining the microstructure in the tested specimen, the shape of the grain has become elongated at the impact end in the region subject to high plastic deformation (Fig. 7). Further a gradient in the grain structure along the impact axis is observed (Fig. $7(\mathrm{a}, \mathrm{b}))$.

The mass of the fragments for each specimen tested has been measured. The results are displayed in Fig. 8 and the maximum measured mass debris is $m_{\text {debris }}=4 \mathrm{~g}$, which is $24 \%$ of the total specimen mass. The increase in the total mass of fragments with impact velocity has been reported for the ring expansion test. $^{8}$

The stress $\sigma$ in the specimen may be derived, and there exists several formulas to derive the stress that

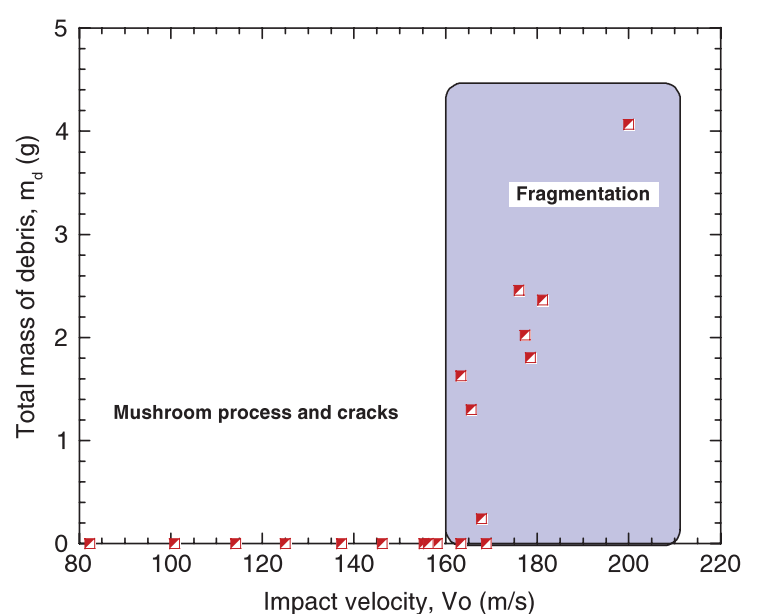

Figure 8 Mass loss by the specimen after Taylor's test due to fragmentation. 


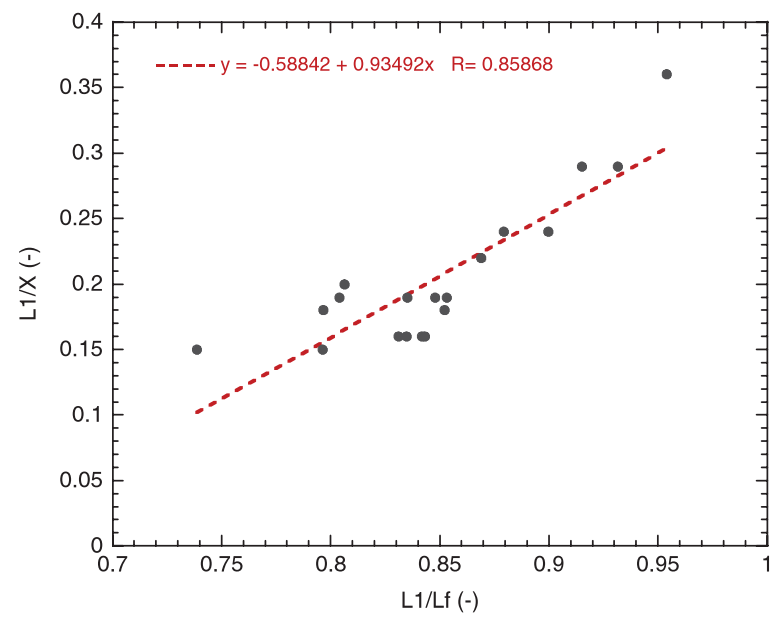

Figure 9 Determination of $m$ and $b$ based from experiments results.

have been reported in Refs. 14, 10, 15. The model reported in Ref. 14 will be used to analyze Taylor test in this article (Fig. 4). The relationship between the elastic part and the final length of the specimen after impact (Fig. 9) is important. Applying a linear approximation to this relationship, the parameter $m$ and $b$ can be defined as reported in Ref. 14. The experimental values obtained in this article for the brass material are $m=0.953$ and $b=-0.605$.

The parameter $\beta$ may be determined in the following equation. The parameter is changing with the level of strain and will estimate the hardening rate of the stress with plastic strain.

$$
\beta(\epsilon)=1+m \cdot \epsilon
$$

where $\epsilon$ is the strain in the specimen derived using Eq. 2.

The next step in the analysis procedure ${ }^{14}$ is to identify the constant $\sigma_{0}$ through $\sigma_{0}=\sigma / 1+\epsilon$. This parameter is derived from the quasi-static test result using $\sigma-\epsilon$. At large deformation the average value converges to $\sigma_{0}=466 \mathrm{MPa}$ (Fig. 10).

The parameters will establish the stress level, $\sigma$, in the specimen under dynamic loading through the following equation

$$
\sigma(\epsilon)=(1+\epsilon)\left\{\sigma_{0}+\frac{[1-\beta(\epsilon)]^{2}}{\epsilon} \rho V^{2}\right\}
$$

where $\rho$ is the density of the brass, $\rho=8460 \mathrm{~kg} / \mathrm{m}^{3}$.

Another frequently used equations to derive the flow stress $\sigma$ from an instrumented Taylor's test $\operatorname{are}^{10,15}$

$$
\sigma=\frac{\rho V^{2}(L-X)}{2\left(L-L_{1}\right) \ln \left(\frac{L}{X}\right)}
$$

$$
\sigma=-\left(\frac{\rho V^{2}}{2}\right)\left[\ln \left(\frac{\left(\frac{L_{1}}{L}-0.12\right)}{0.88}\right)\right]^{-1}
$$

The stress $\sigma$ value obtained through Eqs 6 and 7 will have no dependency on the plastic strain level attained in the specimen in contrary with Eqs 4 and 5 . The comparison between the results obtained under dynamic loading using the Hopkinson bar test and the Taylor's test are displayed in Fig. 11., It was reported $^{10}$ that shape of the specimen can influence the $\sigma$ derived using Eq. 6, but the deviation is within $10 \%$. The results in this paper suggest that the error can exceed $50 \%$ at high plastic strain.

Figure 11 shows that it is possible to describe the dynamic behavior of materials including hardening at high strain rate through Eq. 5. However, Eqs 6 and 7, based on a simplified approach do not allow to define properly the stress level (see Fig. 11). It is observed for large strains a decrease of the stress $\sigma$. In fact, Eq. 7 can be used to define the stress intensity for the strains lower than 0.15 . The relation proposed by Wilkins, ${ }^{15}$ Eq. 7., induced an error less than $10 \%$ if the strain level is lower than 0.2. However, the hardening may not be described and a stress plateau is observed from $0<\epsilon \leq 0.2$.

This analyze proof that only Eq. 5 is available to describe properly the stress level induced to the specimen during Taylor's test. Other equations, Eqs 6 and 7 , are in disagreement in term of predictions with experimental measurements.

\section{Thermal Softening Effect}

Numerical simulations using finite element analysis have been performed to estimate the thermal softening in the specimen for the Taylor test. The three-dimensional model is built in ABAQUS/Explicit. The model consists of two parts: a specimen (impactor) and rigid wall (impacted structure). Both parts are discretized with C3D8R finite elements (8node elements with a linear shape function and reduced integration). The description of the initial impact velocity is necessary to define strain, Eq. 2, strain rate, Eq. 3, and stress level attained, Eqs 5-7. The impacted structure is given a rigid definition which is fully restrained. The contact conditions are defined using a friction coefficient of 0.2. Because of the large deformation of the finite elements mesh, an Arbitrary Lagrangian Eulerian (ALE) method of finite element analysis is used to avoid heavily distorted elements in the mesh at large deformation. A thermoviscoplastic model is selected to describe the 

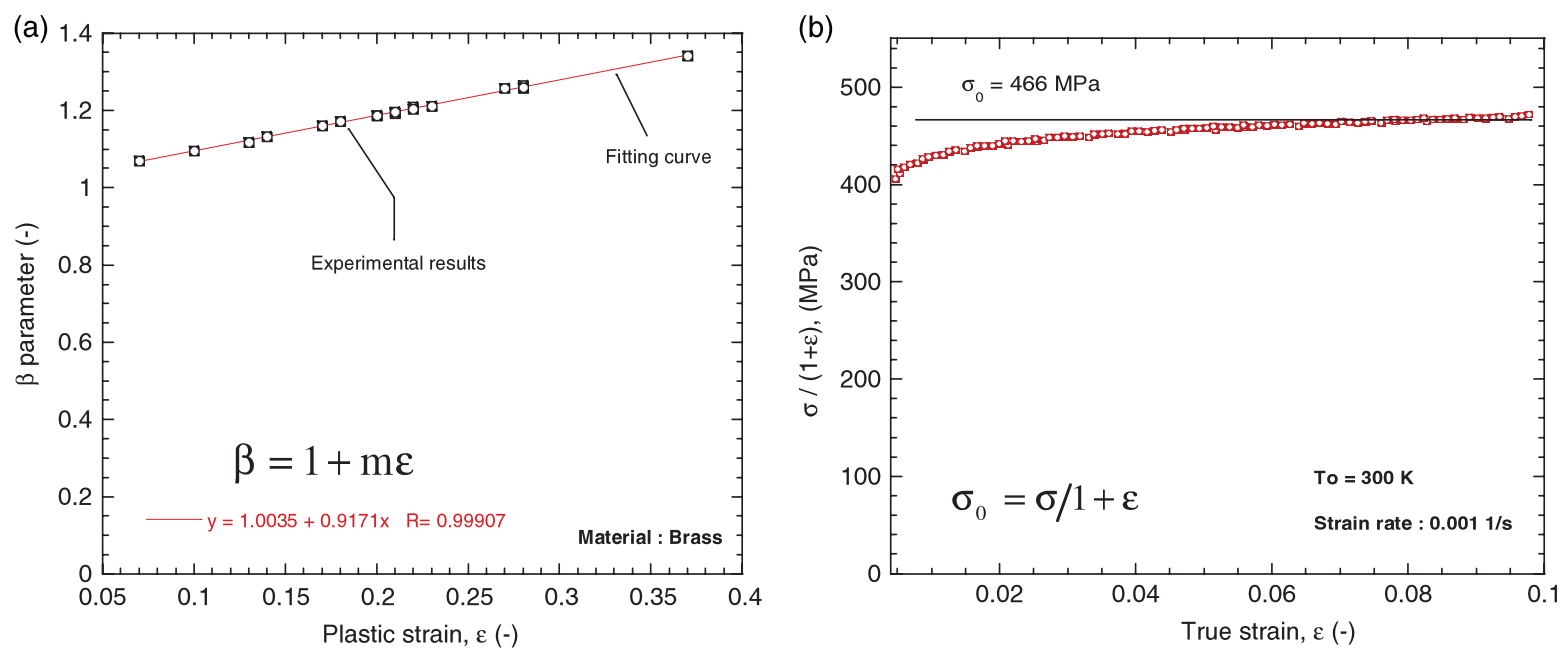

Figure 10 (a) Determination of the parameter Eq. 4; (b) determination of the reference stress to estimate dynamic behavior of material, Eq. 5.

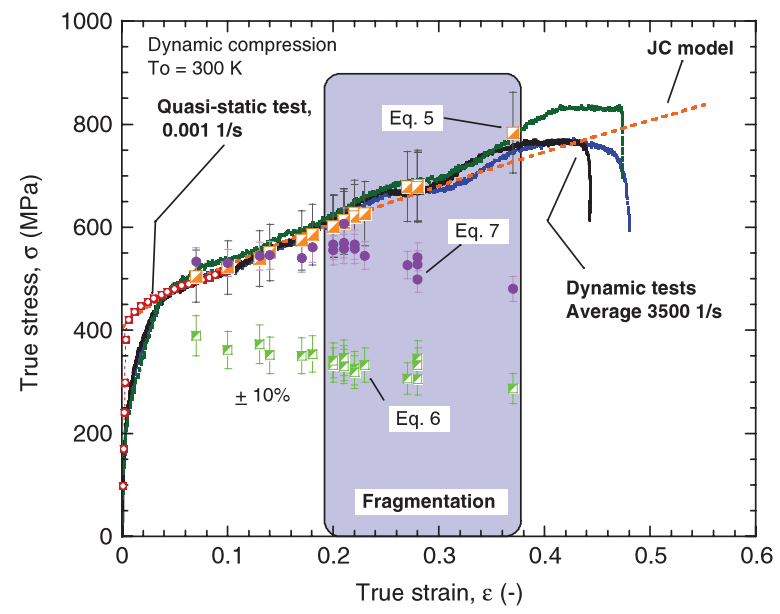

Figure 11 Comparing dynamic test results obtained using Hopkinson compression bar and Taylor's impact tests.

behavior of the material. The model chosen is $\mathrm{JC}^{16}$

$$
\begin{aligned}
\sigma(\epsilon, \dot{\epsilon}, T)= & \left(A+B \epsilon^{n}\right)\left[1+C \ln \left(\frac{\dot{\epsilon}}{\dot{\epsilon}_{0}}\right)\right] \\
& {\left[1-\left(\frac{T-T_{0}}{T_{0}-T_{m}}\right)^{m^{*}}\right] }
\end{aligned}
$$

where $A$ is the yield stress, $B$ and $n$ describe the strain hardening of the material, $C$ is the strain rate sensitivity and $m^{*}$ is the temperature sensitivity.

The brass material is not strain rate sensitive in the tested strain rate range (Fig. 2). Using the results in this article (Fig. 2), the coefficients in the JC model were determined using a least squares fit method, Table 1 . The results obtained from experiments and
Table 1 Coefficients for the JC model used to define the dynamic behavior of brass

\begin{tabular}{lccccc}
\hline$A(\mathrm{MPa})$ & $B(\mathrm{MPa})$ & $n(-)$ & $T_{0}(\mathrm{~K})$ & $T_{\mathrm{m}}(\mathrm{K})$ & $m^{\star}(-)$ \\
\hline 403.51 & 674.638 & 0.7374 & 300 & 1173 & 1.132 \\
\hline
\end{tabular}

the JC model are compared in Fig. 11, and it is observed they are in good agreement (Fig. 11).

Using the material description (Eq. 8), numerical simulations have been performed to determine the strain distribution along the brass specimen The numerical simulation applies only in the range where fragmentation is not observed in the test piece. The deformed shape and resulting strain distribution obtained from the numerical simulation is displayed (Fig. 12).

The local strain values are compared with experiments in term of minimum and maximum strain distribution (Fig. 6). Thus using Eq. 2 and for $V=125 \mathrm{~m} / \mathrm{s}$ the strain level based on experiment is close to $\epsilon_{\text {local }}=0.14$. It is observed that the strain level calculated, Eq. 2., allows to define an average value corresponding to the transition zone (Fig. 12). The plastic strain at the impact face of the specimen is very high and hence a high strain gradient is observed along the specimen in this zone. The numerical simulation enables the change in strength properties along the specimen to be determined together with a relationship to the grain size and shape (Fig. 7). The different impact velocities may be applied in the numerical simulations to derive values of flow stress in the brass specimen which are dependent on the initial impact velocity (Fig. 13). The figure displays 


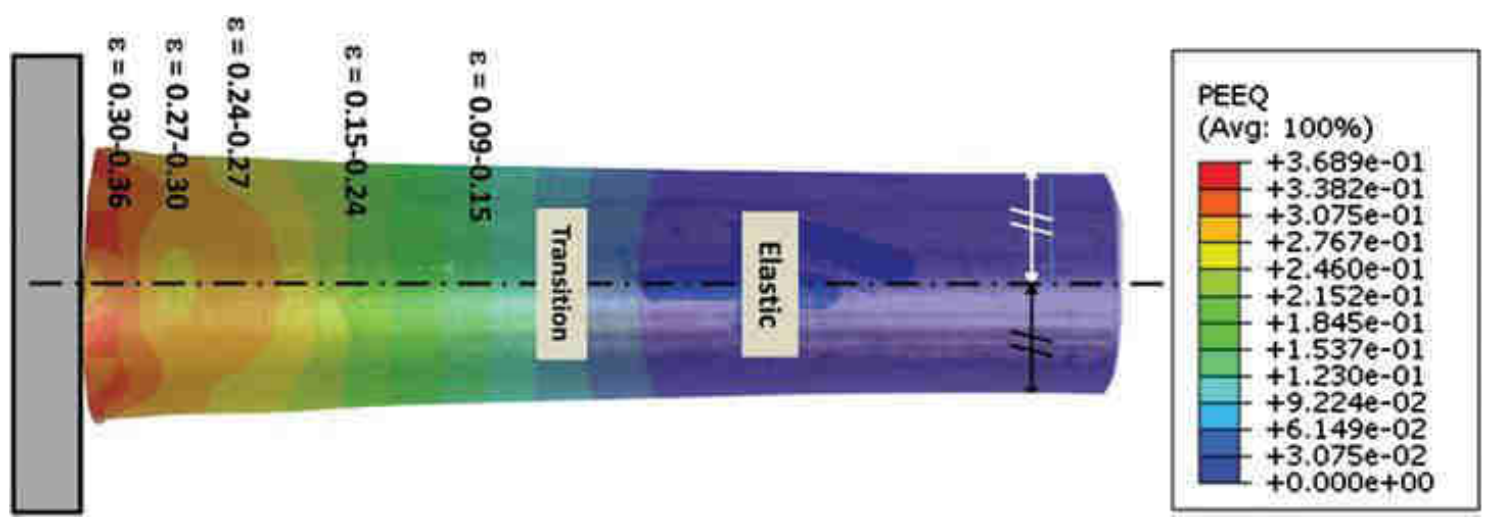

Figure 12 Result of the numerical model displaying the equivalent plastic strain distribution across the deformed shape of the brass specimen after dynamic impact, comparison between experiment and numerical simulation, using $\mu=0.2$, in term of shape for $V=125 \mathrm{~m} / \mathrm{s}$.

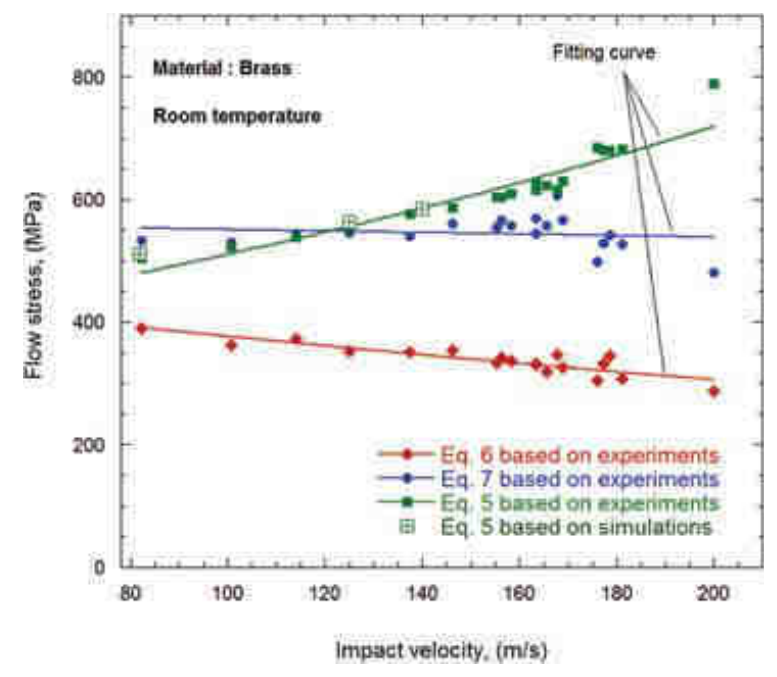

Figure 13 Effect of initial impact velocity on the flow stress using Eqs 5-7 and using numerical results linked to Eq. 5.

the flow stress obtained experimentally and numerically using Eqs 5-7. Different dynamic test methods such as SHPB, Taylor's test, and the conventional hydraulic compression machine, provide a series of experiments covering a wide range strain rates in the range $10^{-4} \leq \dot{\epsilon}<10^{4} \mathrm{l} / \mathrm{s}$. For material with strain rate sensitivity, the nonlinear part, Fig. 2, may be defined and model precisely follow the experimental results. ${ }^{17}$ The high strain rate sensitivity is the key point to model instabilities, ${ }^{5,18}$ damage, and as final stage dynamic fracture. ${ }^{18,19}$

\section{Conclusions}

The article reports that the Taylor's test may be used to determine the dynamic behavior of material from measurements of the final shape of the specimen. Thus, the tests can complete the results obtained using SHPB technique. The Taylor test is generally easier to use in comparison with SHPB where a good understanding of elastic wave analysis is important. ${ }^{6}$ It is also reported that just few parameters from dynamic tests are necessary to have a complete description of the material behavior description. A quasi-static test is also required. The Taylor test not only allows to obtain a description of the material behavior but provides information about the failure process. For brass, the critical velocity may be determined at the initiation of fragmentation of the material.

\section{Acknowledgment}

Authors thank to The National Centre of Research and Development for financial support under the grant WND-DEM-1-203/00. Authors thank Dr R. Pesci from LEM3-ENSAM, France for preparation of the microscope photo of the brass.

\section{References}

1. Nussbaum, J., and Faderla, N., "Evaluation of Strength Model Parameters from Taylor Impact Tests," Procedia Engineering 10: 3453-3458 (2011).

2. Xiao, X., Zhang, W., Wei, G., Mu, Z., and Guo, Z., "Experimental and Numerical Investigation on the Deformation and Failure Behavior in the Taylor Test," Materials and Design 32: 2663-2674 (2011).

3. Wang, B., Zhang, J., and Lub, G., "Taylor Impact Test for Ductile Porousmaterials - Part 2: Experiments," International Journal of Impact Engineering 28: 499-511 (2003).

4. Xiao, X., Zhang, W., Wei, G., and Mu, Z., "Effect of Projectile Hardness on Deformation and Fracture 
Behavior in the Taylor Impact Test," Materials and Design 31: 4913-4920 (2010).

5. Couque, H. "On the Use of the Symmetric Taylor Test to Evaluate Dynamic Ductile Compression Fracture Properties of Metals," Proceedings of the 5th International Conference on Structures Under Shock and Impact, Computational Mechanics Inc, Billerica, MA, USA (1998).

6. Jankowiak, T., Rusinek, A., and Lodygowski, T., "Validation of the Klepaczko-Malinowski Model for Friction Correction and Recommendations on Split Hopkinson Pressure Bar," Finite Elements in Analysis and Design 47: 1191-1208 (2011).

7. Iwamoto, T., and Yokoyama, T., "Effects of Radial Inertia and End Friction in Specimen Geometry in Split Hopkinson Pressure Bar Tests: A Computational Study," Mechanics of Materials 51: 97-109 (2012).

8. Rusinek, A., and Zaera, R., "Finite Element Simulation of Steel Ring Fragmentation Under Radial Expansion," International Journal of Solids and Structures 44: 5611-5634 (2007).

9. W.J. Phillips, Engineering Design Handbook-Sabot Technology Engineering, US Government Agency, Washington, DC (1972), 2-4.

10. Taylor, G., "The Use of Flat-Ended Projectiles for Determining Dynamic Yield Stress I," Theoretical Considerations. Proceedings of the Royal Society of London. Series A: Mathematical and Physical Sciences 194: 289-299 (1948).

11. Ren, Y., Tan, C.W., Zhang, J., and Wang, F., "Dynamic Fracture of Ti-6Al-4V Alloy in Taylor Impact Test," Transactions of Nonferrous Metals Society of China 21: 223-235 (2011).
12. Julien R. Miseen place d'un essai de Taylor, validation expérimentale et étudenumérique, Master Dissertation, ENIM-LaBPS (2012).

13. Teng, X., Wierzbicki, T., Hiermaier, S., and Rohr, I., "Numerical Prediction of Fracture in the Taylor Test," International Journal of Solids and Structures 42: 2929-2948 (2005).

14. Jones, S.E., Drinkard, J.A., Rule, W.K., and Wilson, L.L., "An Elementary Theory for the Taylor Impact Test," International Journal of Impact Engineering 21: $1-13$ (1998).

15. Wilkins, M.L., and Guinan, M.N., "Impact of Cylinders on a Rigid Boundary," Journal of Applied Physics 44: 1200-1207 (1973).

16. Johnson, G.R., Cook, W.H. "A Constitutive Model and Data for Metals Subjected to Large Strains, High Strain Rates and High Temperatures," Proceedings of 7th International Symposium on Ballistics, Hague, Netherlands (1983), pp. 541-547.

17. Rusinek, A., Rodriguez-Marinez, J.A., Klepaczko, J.R., and Pecherski, R., "Analysis of Thermo-Visco-Plastic Behaviour of Six High Strength Steels," Materials and Design 30: 1748-1761 (2009).

18. Łodygowski, T., Rusinek, A., Jankowiak, T., and Sumelka, W., "Selected Topics of High Speed Machining Analysis," Engineering Transactions 60: 69-96 (2012).

19. Miguelez, H., Zaera, R., Rusinek, A., Moufki, A., and Molinari, A., "Numerical Modelling of Orthogonal Cutting: Influence of Cutting Conditions and Separation Criterion," Journal de Physique IV 134: 417-422 (2006). 